\title{
Characterization of the multigene family TaHKT 2;1 in bread wheat and the role of gene members in plant $\mathrm{Na}^{+}$and $\mathrm{K}^{+}$status
}

\author{
HA Chandima K Ariyarathna ${ }^{1,2}$, Tanveer Ul-Haq ${ }^{1,2,3}$, Timothy D Colmer ${ }^{1}$ and Michael G Francki $\mathrm{i}^{2,4^{*}}$
}

\begin{abstract}
Background: A member of the TaHKT2;1 multigene family was previously identified as a $\mathrm{Na}^{+}$transporter with a possible role in root $\mathrm{Na}^{+}$uptake. In the present study, the existing full-length cDNA of this member was used as a basis to query the International Wheat Genome Survey Sequence to identify all members of the TaHKT2;1 family. Individual TaHKT2;1 genes were subsequently studied for gene and predicted protein structures, promoter variability, tissue expression and their role in $\mathrm{Na}^{+}$and $\mathrm{K}^{+}$status of wheat.

Results: Six TaHKT2;1 genes were characterized which included four functional genes (TaHKT2;1 7AL-1, TaHKT2;1 7BL-1, TaHKT2;1 7BL-2 and TaHKT2;1 7DL-1) and two pseudogenes (TaHKT2;1 7AL-2 and TaHKT2;1 7AL-3), on chromosomes 7A, $7 \mathrm{~B}$ and 7D of hexaploid wheat. Variability in protein domains for cation specificity and in cis-regulatory elements for salt response in gene promoters, were identified amongst the functional TaHKT2;1 members. The functional genes were expressed under low and high $\mathrm{NaCl}$ conditions in roots and leaf sheaths, but were down regulated in leaf blades. Alternative splicing events were evident in TaHKT2;1 7AL-1. Aneuploid lines null for each functional gene were grown in high $\mathrm{NaCl}$ nutrient solution culture to identify potential role of each TaHKT2;1 member. Aneuploid lines null for TaHKT2;1 7AL-1, TaHKT2;1 7BL-1 and TaHKT2;1 7BL-2 showed no difference in $\mathrm{Na}^{+}$concentration between Chinese Spring except for higher $\mathrm{Na}^{+}$in sheaths. The same aneuploid lines had lower $\mathrm{K}^{+}$in roots, sheath and youngest fully expanded leaf but only under high $(200 \mathrm{mM}) \mathrm{NaCl}$ in the external solution. There was no difference in $\mathrm{Na}^{+}$or $\mathrm{K}^{+}$concentration for any treatment between aneuploid line null for the TaHKT2;1 7DL-1 gene and Chinese Spring.

Conclusions: TaHKT2;1 is a complex family consisting of pseudogenes and functional members. TaHKT2;1 genes do not have an apparent role in controlling root $\mathrm{Na}^{+}$uptake in bread wheat seedlings under experimental conditions in this study, contrary to existing hypotheses. However, TaHKT2;1 genes or, indeed other genes in the same chromosome region on $7 \mathrm{AL}$, are candidates that may control $\mathrm{Na}^{+}$transport from root to sheath and regulate $\mathrm{K}^{+}$levels in different plant tissues.
\end{abstract}

Keywords: IWGSS, Cis regulatory elements, Gene expression, Aneuploid lines, Tissue Na ${ }^{+}$, Tissue K ${ }^{+}$

\section{Background}

Saline soils are a challenge to cereal production in many regions of the world. Osmotic and ion-specific damage that significantly reduces crop growth in saline soils is largely due to excess of $\mathrm{Na}^{+}$and $\mathrm{Cl}^{-}$ions [1,2]. In bread wheat, a balance between restricting $\mathrm{Na}^{+}$net uptake at

\footnotetext{
* Correspondence: michael.francki@agric.wa.gov.au

${ }^{2}$ State Agricultural Biotechnology Centre, Murdoch University, Murdoch 6150, Western Australia

${ }^{4}$ Department of Agriculture and Food Western Australia, South Perth 6151, Western Australia

Full list of author information is available at the end of the article
}

roots and subsequent transport into shoots and subcellular compartmentation to cope with unfavourable levels of $\mathrm{Na}^{+}$is needed to maintain ion homeostasis for plant growth and development under saline conditions $[3,4]$. The regulation of $\mathrm{Na}^{+}$transport and its genetic basis is, therefore, of significant interest in order to assist in development of targeted strategies for enhanced salinity tolerance in crops.

A major portion of $\mathrm{Na}^{+}$exclusion $(>98 \%)$ in bread wheat is accomplished by restricting net $\mathrm{Na}^{+}$uptake at the soil-root interface and net xylem loading in roots [2], yet a number of channels and transporters facilitate 
$\mathrm{Na}^{+}$influx when $\mathrm{Na}^{+}$concentration is high in the soil solution [5-8]. Channel and transporter proteins are potential targets to reduce $\mathrm{Na}^{+}$net uptake by roots and have been a major focus to investigate their role in crop tolerance to salinity. Electrophysiological observations and pharmacology of ${ }^{22} \mathrm{Na}^{+}$tracer influxes in cereal roots support the hypothesis that the bulk of $\mathrm{Na}^{+}$influx is mediated by voltage-independent, non-selective cation channels (VICs/NSCCs) [9-11]. In addition, two transporters LCT1 [12,13] and HKT2;1[14] can mediate high and/or low-affinity $\mathrm{Na}^{+}$transport in wheat. While both VICs/NSCCs [15] and LCT1 [13] facilitate $\mathrm{Ca}^{2+}$ dependant unidirectional influx of various cations, TaHKT2;1 mediates $\mathrm{Ca}^{2+}$ independent influx of $\mathrm{Na}^{+}$and $\mathrm{K}^{+}[16,17]$. Although, TaHKT2;1 is a $\mathrm{Na}^{+} / \mathrm{K}^{+}$co-transporter, the protein has a minor significance in $\mathrm{K}^{+}$nutrition as $\mathrm{Na}^{+}$coupled $\mathrm{K}^{+}$uptake has limited physiological relevance in terrestrial species [18]. Therefore, among the genes encoding candidate proteins involved in root $\mathrm{Na}^{+}$influx, TaHKT2; 1 is of particular interest in crop breeding because of its high specificity for $\mathrm{Na}^{+}$and the potential to manipulate TaHKT2;1 genes without largely interfering with the homeostasis of nutritionally important ions (e.g., $\mathrm{K}^{+}, \mathrm{Ca}^{2+}$ ) in plants.

TaHKT2;1 has a Gly-Gly-Gly-Gly type $\mathrm{K}^{+} / \mathrm{Na}^{+}$selectivity pore $[19,20]$ and when expressed in Xenopus oocytes and yeast heterologous systems, preferentially mediates high affinity $\mathrm{K}^{+}$uptake when external $\mathrm{Na}^{+}$is at sub-millimolar levels, but facilitates low-affinity $\mathrm{Na}^{+}$ influx when millimolar levels of external $\mathrm{Na}^{+}$are in excess of $\mathrm{K}^{+}[16,21,22]$. The ion transport properties of TaHKT2; 1 were determined when point mutations within the TaHKT2;1 gene improved $\mathrm{K}^{+}$specificity and reduced $\mathrm{Na}^{+}$influx in Xenopus oocytes and yeast [21,23]. Down regulation of TaHKT2;1 in transgenic bread wheat by expressing anti-sense or truncated sense constructs reduced $\mathrm{Na}^{+}$levels in $\mathrm{K}^{+}$starved seedling roots [24]. Since the gene is expressed in the cortical cells of roots, alongside in xylem parenchyma in leaves, it is possible that the protein encoded by TaHKT2;1 is associated with root $\mathrm{Na}^{+}$uptake and translocation [24]. Therefore, it appears that under saline conditions TaHKT2;1 is responsible for substantial $\mathrm{Na}^{+}$influx into roots of bread wheat and transport to other parts of the plant.

TaHKT2; 1 has been identified as a multi-gene family consisting of five individual members distributed across homeologous chromosome group 7 in bread wheat [25]. Although previous studies identified the function of $\mathrm{Na}^{+}$ transport in one member of the TaHKT2;1 gene family in heterologous systems [21,23] and in transgenic plants by down-regulation of one or more genes [24], the contribution of each member of the gene family and their interactions to control ion accumulation in wheat remains unknown. This study aimed to understand the organization and variability of each member of the TaHKT2;1 gene family, transcriptional regulation, their encoded proteins, and potential contributions to controlling $\mathrm{Na}^{+}$and $\mathrm{K}^{+}$ status in bread wheat. The study used an existing full length cDNA (FL-cDNA) sequence (U16709) as a basis to select and characterize all members of the TaHKT2;1 gene family using the International Wheat Genome Survey Sequence (IWGSS) (www.wheatgenome.org).

\section{Results}

Organization and structure of TaHKT2; 1 multi-gene family The FL-cDNA of TaHKT2;1, U16709, was used as query sequence in BLASTN analysis of IWGSS to identify members of the TaHKT2;1 gene family in hexaploid wheat. Six significant hits having greater than $90 \% \mathrm{nu}-$ cleotide identity with the FL-cDNA were retrieved that identified three TaHKT2;1 genes on the long arm of chromosome 7A (TaHKT2;1 7AL-1, TaHKT2;1 7AL-2, TaHKT2;1 7AL-3), two genes on the long arm of $7 \mathrm{~B}$ (TaHKT2;1 7BL-1, TaHKT2;1 7BL-2), and one on the long arm of 7D (TaHKT2;1 7DL-1). The six genes were further studied for gene structure and sequence variability. Gene structure was analysed by splice junction prediction software, and subsequently validated in DNA sequence alignments with the FL-cDNA, U16709, revealed three exons interrupted by two introns for each gene (Figure 1) with intron splice junction sites having the conserved motif, 5' GT- AG 3'. TaHKT2;1 7AL-2 and TaHKT2;1 7AL-3 were identical in their introns and exons and each had a single nucleotide deletion at +191 bp in exon 1 relative to the other genes on chromosome $7 \mathrm{~A}, 7 \mathrm{~B}$ and $7 \mathrm{D}$ whereby the translated sequences predicted an in-frame stop codon causing pre-mature termination and a significantly truncated protein of 65 amino acid residues. Therefore, it appeared that TaHKT2;1 7AL-2 and TaHKT2;1 7AL-3 were duplicated pseudogenes. Accordingly, TaHKT2;1 represented a multi-gene family of six individual genes in bread wheat of which four (TaHKT2;1 7AL-1, TaHKT2;1 7BL-1, TaHKT2;1 7BL-2 and TaHKT2;1 $7 D L-1)$ were identified as functional members.

The functional TaHKT2;1 genes were further analysed using multiple DNA sequence alignments and revealed 90-94\% nucleotide identity (Table 1 ). The two genes, TaHKT2;1 7BL-1 and TaHKT2;1 7BL-2 were identical in introns and exons (thus hereafter designated as TaHKT2;1 $7 B L-1 /-2)$ and shared $100 \%$ nucleotide identity with the full-length cDNA, U16709, so it was reasonable to assume that these genes on $7 \mathrm{BL}$ were the source of the query cDNA sequence. TaHKT2;1 $7 B L-1 /-2$ were subsequently used in pairwise sequence comparisons with TaHKT2;1 $7 A L-1$ and TaHKT2;1 7DL-1 to identify variations in intron and exon regions (Figure 1 and Table 2). Sequence divergence in the intron regions of the TaHKT2;1 genes were clearly evident, including SNPs and INDELs (Table 3). 


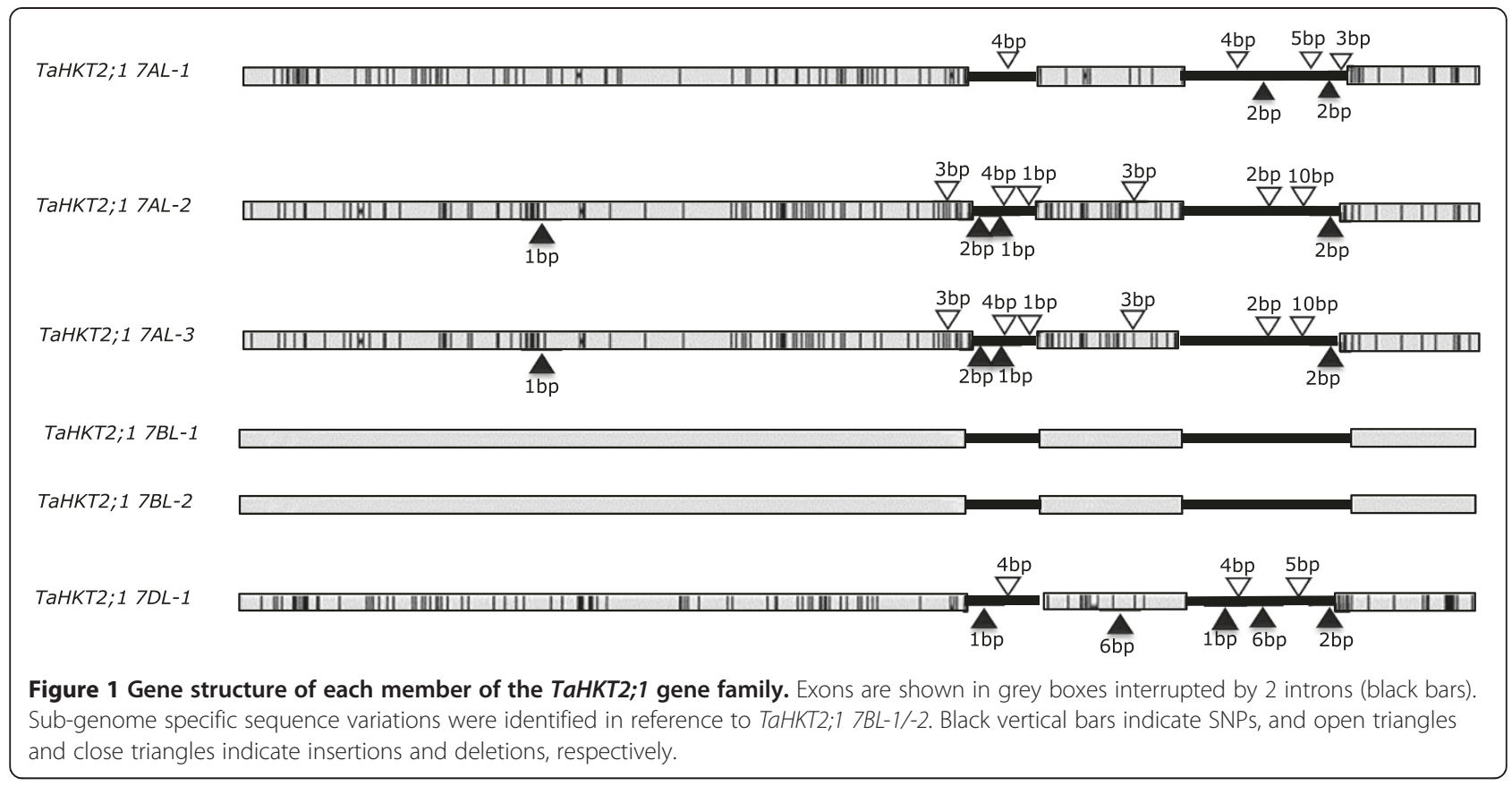

Exon sequence variation between TaHKT2;1 7BL-1/-2 and genes on 7A and 7D were largely represented by SNPs, whereby $36 \%$ of the SNPs in TaHKT2;1 7AL-1 and $41 \%$ of the SNPs in TaHKT2;1 7DL-1 represented nonsynonymous substitutions (Table 3 ). Thus, sequence comparisons against TaHKT2;1 7BL-1/-2 identified members of TaHKT2; 1 gene family exhibiting a degree of exon variability resulting in predicted protein differences.

\section{Analysis of predicted proteins of TaHKT2; 1 multi-gene family}

Functional members of TaHKT2;1 gene family on 7AL and 7BL encoded proteins of 533 amino acids whereas the gene on 7DL encoded a protein of 531 amino acids (Table 2) having $91 \%$ to $93 \%$ protein identity (Table 1 ) with TaHKT2;1 7BL-1/-2. Sequence alignment (Figure 2) coupled with analysis of hydrophobicity (Additional file 1: Figure S1) and 3D structures of the predicted proteins revealed the topology of four sequentially arranged membrane-pore-membrane (MPM) domains in each

Table 1 Percent DNA sequence and amino acid (parentheses) identity between functional members of the TaHKT2;1 gene family

\begin{tabular}{lccc}
\hline Gene & TaHKT2;1 7AL-1 & TaHKT2;1 7BL-1 & TaHKT2;1 7DL-1 \\
& & TaHKT2;1 7BL-2 & \\
\hline TaHKT2;1 7AL-1 & - & & \\
TaHKT2;1 7BL-1 and & $91.3(92.5)$ & - & \\
TaHKT2;1 7BL-2 & & & - \\
TaHKT2;1 7DL-1 & $94.3(93.4)$ & $90.1(91.6)$ & - \\
\hline
\end{tabular}

protein (Figure 2). Glycine molecules at Gly91, Gly246, Gly370 and Gly473 that form the selectivity pore filters $[19,20]$ were conserved in each protein (Figure 2) predicting that each functional member has potential to mediate both $\mathrm{K}^{+}$and $\mathrm{Na}^{+}$transport. Interestingly, several amino acid substitutions were identified in the close proximity of filter glycine residues on first, second and fourth MPM domains of TaHKT2;1 7AL-1 and TaHKT2;1 7DL-1 compared to TaHKT2;1 $7 B L-1 /-2$ (Figure 2). In the first $\mathrm{M}_{\mathrm{a}} \mathrm{P}_{\mathrm{a}} \mathrm{M} 22_{\mathrm{a}}$, Ile95 in TaHKT2;1 $7 B L-1 /-2$ was substituted by Val, an amino acid having similar physical properties, in both TaHKT2;1 7AL-1 and TaHKT2;1 7DL-1. The substitution Thr96 for another hydrophilic but larger amino acid Lys was shared in both TaHKT2;1 7AL-1 and TaHKT2;1 7DL-1. The second $\mathrm{M}_{\mathrm{b}} \mathrm{P}_{\mathrm{b}} \mathrm{M} 2_{\mathrm{b}}$ identified two substitutions, one at Ala240 for Ser, a more hydrophilic amino acid in the same size range and Cys 242 for a large hydrophobic amino acid Phe in TaHKT2;1 7DL-1. The fourth $\mathrm{M}_{\mathrm{d}} \mathrm{P}_{\mathrm{d}} \mathrm{M} 2_{\mathrm{d}}$ identified Ala472 in both TaHKT2;1 $7 A L-1$ and TaHKT2;1 7DL-1, substituted for Val, an amino acid carrying large aliphatic hydrophilic side chains. Altered physical properties and steric hindrance caused by the amino acid substitutions could, therefore, potentially change structural properties of the filters and manifest modified protein functions for ion selectivity and transport.

\section{Promoter analysis of functional TaHKT2;1 members}

Promoter diversity was investigated in functional members of the TaHKT2;1 gene family by analysis of $2000 \mathrm{bp}$ region up-stream of the predicted translation start site. The core promoter element, TATAA box (-69 bp) was 
Table 2 Attributes of exons, introns and proteins of functional members of the TaHKT2;1 gene family

\begin{tabular}{|c|c|c|c|c|}
\hline & & TaHKT2;1 7AL-1 & $\begin{array}{l}\text { TaHKT2;1 7BL-1 } \\
\text { TaHKT2;1 7BL-2 }\end{array}$ & TaHKT2;1 7DL-1 \\
\hline \multirow[t]{7}{*}{ Exon } & Exon 1 length (bp) & 1172 & 1172 & 1172 \\
\hline & Exon 2 length (bp) & 228 & 228 & 222 \\
\hline & Exon 3 length (bp) & 202 & 202 & 202 \\
\hline & Non-synonymous SNPs & 35 & - & 43 \\
\hline & Total number of SNPs & 95 & & 104 \\
\hline & Insertions (bp) & 0 & - & 0 \\
\hline & Deletions (bp) & 0 & - & 6 \\
\hline \multirow[t]{5}{*}{ Intron } & Intron 1 length (bp) & 130 & 126 & 129 \\
\hline & Intron 2 length (bp) & 263 & 256 & 256 \\
\hline & SNPS & 59 & - & 61 \\
\hline & Insertions (bp) & 16 & - & 13 \\
\hline & Deletions (bp) & 4 & - & 10 \\
\hline \multirow[t]{2}{*}{ Protein } & Amino acid length & 533 & 533 & 531 \\
\hline & $\begin{array}{l}\text { Amino acid } \\
\text { substitutions }\end{array}$ & 31 & - & 35 \\
\hline
\end{tabular}

SNPs and INDELS were identified using TaHKT2;1 7BL-1/ TaHKT2;1 7BL-2 as the reference sequence.

conserved in all functional members of the TaHKT2;1 family. Although TaHKT2;1 $7 B L-1 /-2$ were identical in exon and intron sequences, they shared only $42.7 \%$ DNA sequence identity between promoters. The promoter region of TaHKT2;1 7AL-1, and TaHKT2;1 7DL-1 genes showed $65.8 \%$ and $43.5 \%$ DNA sequence identity, respectively, compared with TaHKT2;1 7BL-1/-2. Table 3 summarizes the number and type of cis-acting regulatory elements (CREs) identified in promoters of functional members of the TaHKT2;1 family using the PLANTcare and PLACE databases. Promoters of all functional TaHKT2;1 genes contained a number of CREs known to be involved in salt activated response in plants and each gene shared at least five CREs of different categories. Therefore, it appeared that salt stress-activated transcription factors (TFs) interact with CREs to regulate TaHKT2;1 genes.

\section{Analysis of TaHKT2;1 pseudogenes in Triticum species}

The duplicated pseudogenes, TaHKT2;1 7AL-2 and TaHKT2;1 7AL-3, showed an in-frame stop codon in exon 1 resulting in a truncated protein of 65 amino acids (Figure $3 \mathrm{~A}$ ) relative to its functional counterpart, TaHKT2;1 7AL-1. The pseudogenes were examined across selected Triticum species in order to gain further insight into their origin and evolution. The $5^{\prime}$ terminus of exon 1 including $50 \mathrm{bp}$ upstream from the translation start site was amplified from diploid, tetraploid and hexaploid wheats using gene specific primers $5^{\prime} \mathrm{A} 2 / 3 \mathrm{~F}$ and $5^{\prime} \mathrm{A} 2 / 3$ $\mathrm{R}$ (Table 4). Specificity of the primers that were used to

Table 3 Salt induced cis- acting regulatory elements identified in the promoter regions of the functional TaHKT2; 1 genes

\begin{tabular}{|c|c|c|c|c|}
\hline $\begin{array}{l}\text { Cis-regulatory } \\
\text { element }\end{array}$ & $\begin{array}{l}\text { Conserved } \\
\text { sequence motif }\end{array}$ & Gene & Associated families of salt-stress activated TFs & Reference \\
\hline \multirow[t]{2}{*}{ ABRE } & ACGTGG/T & TaHKT2;1 7AL-1(1) & AREB/ABF (ABA responsive element- binding proteins) & {$[26]$} \\
\hline & & TaHKT2;1 7BL-2(1) TaHKT2;1 7DL-1(5) & & \\
\hline AtMYC2 & CACATG & $\begin{array}{l}\text { TaHKT2;1 7AL-1(1) TaHKT2;1 7BL-1(2) } \\
\text { TaHKT2;1 7BL-2(3) TaHKT2;1 7DL-1(5) }\end{array}$ & MYC/MYB (myelocytomatosis/myeloblastosis) & [27] \\
\hline DRE/CRT & CCCGAC & $\begin{array}{l}\text { TaHKT2;1 7AL-1(1) TaHKT2;1 7BL-1(2) } \\
\text { TaHKT2;1 7BL-2(1) TaHKT2;1 7DL-1(1) }\end{array}$ & $\begin{array}{l}\text { CBF/DREB (C-repeat binding factor/dehydration- responsive } \\
\text { element-binding proteins) }\end{array}$ & [28] \\
\hline MYCATERD1 & CATGTG & $\begin{array}{l}\text { TaHKT2;1 7ALL-1(3) TaHKT2;1 7BL-1(2) } \\
\text { TaHKT2;1 7BL-2(3) TaHKT2;1 7DL-1(4) }\end{array}$ & plant specific family of TFs, NAC (No apical meristem) & [29] \\
\hline GT-1 box & GAAAAA & $\begin{array}{l}\text { TaHKT2;1 7BL-1(10) TaHKT2;1 7BL-2(4) } \\
\text { TaHKT2;1 7DL-1(12) }\end{array}$ & Trihelix family, also known as GT factors & [30] \\
\hline W-Box & TTTGACY & $\begin{array}{l}\text { TaHKT2;1 7AL-1(12) TaHKT2;1 7BL-1(10) } \\
\text { TaHKT2;1 7BL-2(10) TaHKT2;1 7DL-1(10) }\end{array}$ & WRKY transcription factors & [31] \\
\hline
\end{tabular}

The number of each element in the promoter represented in each gene is shown in parenthesis. 


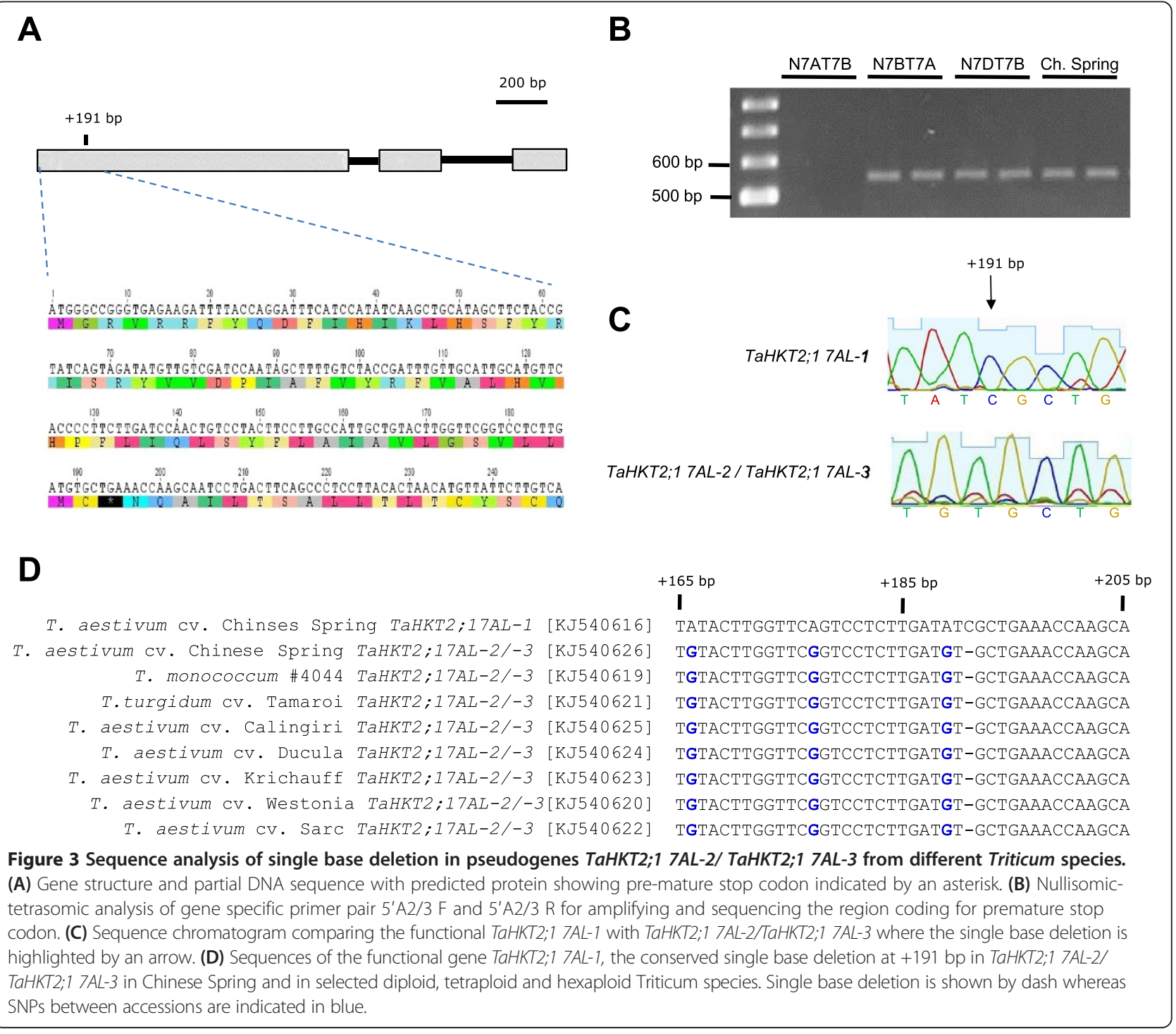


Table 4 Gene specific PCR primers targeting INDELs and SNPs to amplify individual members of the TaHKT2;1 gene family

\begin{tabular}{|c|c|c|c|c|}
\hline Gene & Primer & Primer location (bp) & Primer sequence $5^{\prime}-3^{\prime}$ & $\begin{array}{l}\text { PCR and the annealing } \\
\text { temperature }\left({ }^{\circ} \mathrm{C}\right)\end{array}$ \\
\hline TaHKT2;1 7AL-2 and TaHKT2;1 7AL-3 & $5^{\prime} \mathrm{A} 2 / 3 \mathrm{~F}$ & -56 & GAGACCTATCTTGACACGCAT & Touch down PCR at 55-50 \\
\hline TaHKT2;1 7AL-2 and TaHKT2;1 7AL-3 & $5^{\prime} A 2 / 3 R$ & +489 & GACTCATCACTITGTGCTGC & Touch down PCR at 55-50 \\
\hline TaHKT2;1 7AL-1 & $A 1 F$ & +1325 & GCACCACCCAGTGATGAC & Touch down PCR at 55-50 \\
\hline TaHKT2;1 7AL-1 & A1 R & +1894 & CCAGAAAAGCTGTATCGCA & Touch down PCR at 55-50 \\
\hline TaHKT2;1 7BL-1 and TaHKT2;1 7BL-2 & $\mathrm{B} 1 / 2 \mathrm{~F}$ & +1353 & GAGAACACGAAAGGGAGAGT & Touch down PCR at 55-50 \\
\hline TaHKT2;1 7BL-1 and TaHKT2;1 7BL-2 & $\mathrm{B} 1 / 2 \mathrm{R}$ & +1933 & TCCATAGAGCATGACCGAT & Touch down PCR at 55-50 \\
\hline TaHKT2;1 7DL-1 & DF & +1357 & CGAGCACAAAAGGCAAGA & Touch down PCR at 55-50 \\
\hline TaHKT2;1 7DL-1 & DR & +1955 & TGGACACCGCAAACTCT & Touch down PCR at 55-50 \\
\hline TaHKT2;1 7AL-1 & $\mathrm{FL}: \mathrm{A} 1 \mathrm{~F}$ & -29 & CATTTGTTTCTCCCAGTCG & Standard PCR at 53 \\
\hline TaHKT2;1 7AL-1 & $\mathrm{FL}: \mathrm{A} 1 \mathrm{R}$ & +2180 & CCACACGTTGATAGATAATGTC & Standard PCR at 53 \\
\hline TaHKT2;1 7BL-1 and TaHKT2;1 7BL-2 & $\mathrm{FL}: \mathrm{B} 1 / 2 \mathrm{~F}$ & -19 & CACACTCATACATAGCACCAT & Standard PCR at 53 \\
\hline TaHKT2;1 7BL-1 and TaHKT2;1 7BL-2 & $\mathrm{FL}: \mathrm{B} 1 / 2 \mathrm{R}$ & +2251 & TTCTCTTTCGCTACGATTGT & Standard PCR at 53 \\
\hline TaHKT2;1 7DL-1 & $F L: D F$ & -23 & GTTTCTCACTCATATATAGGACCA & Standard PCR at 56 \\
\hline TaHKT2;1 7DL-1 & $F L: D R$ & +2039 & GTACGCAGCAGTTATACCAG & Standard PCR at 56 \\
\hline
\end{tabular}

amplify the region encoding the premature stop codon in exon 1 was confirmed by the absence of PCR amplicons from nullisomic-tetrasomic lines N7AT7B and N7AT7D (Figure 3B). The single base deletion at $+191 \mathrm{bp}$ in TaHKT2;1 7AL-2/-3 relative to TaHKT2;1 7AL-1 (Figure $3 C$ ) responsible for the in-frame stop codon was conserved in all diploid, tetraploid and hexaploid Triticum accessions analysed (Figure 3D) indicating that the deletion event was an ancient evolutionary sequence variant and the resulting pseudogenes were retained in modern durum and bread wheat accessions. Selection constraints on the genes were estimated by replacement $(K a)$ to silent $(K s)$ ratio [32]. The ratio between the functional genes TaHKT2;1 7AL-1 and TaHKT2;1 7BL-1/-2 was 0.20. Higher ratio value of 0.56 between TaHKT2;1 7AL-2/ -3 and the functional counterpart TaHKT2;1 7AL-1 indicated relaxed selection pressure on the pseudogenes.

\section{Expression of functional members of TaHKT2;1 gene family} The expression of functional members of the TaHKT2;1 gene family were investigated by imposing $\mathrm{NaCl}$ treatments on Chinese Spring seedlings and detection of transcripts specific for each gene in roots, sheaths and leaf blades. After three days exposure at $200 \mathrm{mM} \mathrm{NaCl}$ treatment in the external solution, $\mathrm{Na}^{+}$concentration was 4-fold higher in roots, 3-fold in sheath and 2-fold in leaves, compared to the control plants with no added $\mathrm{NaCl}$ in the external solution (Figure 4A) and, therefore, showed significant $(P<0.01)$ phenotypic differences for transcript analysis of the different TaHKT2;1 genes. Primers were designed to amplify FL-cDNA of each functional member of the TaHKT2;1 gene family and gene specificity of primers was validated using nullisomic- tetrasomic lines (Figure 4B). TaHKT2;1 7AL-1 and TaHKT2; 1 7BL-1/-2 were expressed in roots, sheaths and leaf blades under both low and high $\mathrm{NaCl}$ conditions whilst TaHKT2;1 7DL-1 was identified only in roots and sheaths (Figure 4C). Each functional member of the TaHKT2;1 gene family was down regulated in the leaf blades (Figure 4C). A unique feature of the TaHKT2;1 $7 A L-1$ gene was an additional smaller transcript of approximately $600 \mathrm{bp}$ in length identified only in root and sheath tissues under both $\mathrm{NaCl}$ treated and non-treated conditions (Figure 4C), indicating that alternative splicing was evident for this gene in these tissues. No RT-PCRamplification of TaHKT2;1 7AL-2 or TaHKT2;1 7AL-3 was detected in any of the tissues analysed (data not shown), providing further evidence that these were, indeed, unprocessed pseudogenes.

FL-cDNA transcripts of functional TaHKT2;1 genes expressed in root, sheath and leaf under low and high $\mathrm{NaCl}$ conditions were sequenced. The cDNA sequence for TaHKT2;1 7AL-1 [Genbank: KJ540616]; TaHKT2;1 7BL-1/-2 [Genbank: U16709] and TaHKT2;1 7DL-1 [Genbank: KJ540618] were identical from each tissue and were in perfect agreement with the predictions of gene structure in Figure 1 when aligned against the cognate genomic DNA sequence. Sequence analysis identified a $571 \mathrm{bp}$ alternatively spliced transcript [Genbank: KJ540617] from TaHKT2;1 7AL-1 encoding a predicted protein of 133 amino acids. Alignment with genomic DNA identified a splice site within exon 1 resulting in the deleting of exon 2 and exon 3 and intervening introns relative to its larger cDNA counterpart [Genbank: KJ540616]. The alternatively spliced TaHKT2;1 7AL-1 sequence had the dinucleotide motif $5^{\prime}$-AT and AC- 3 ' at 

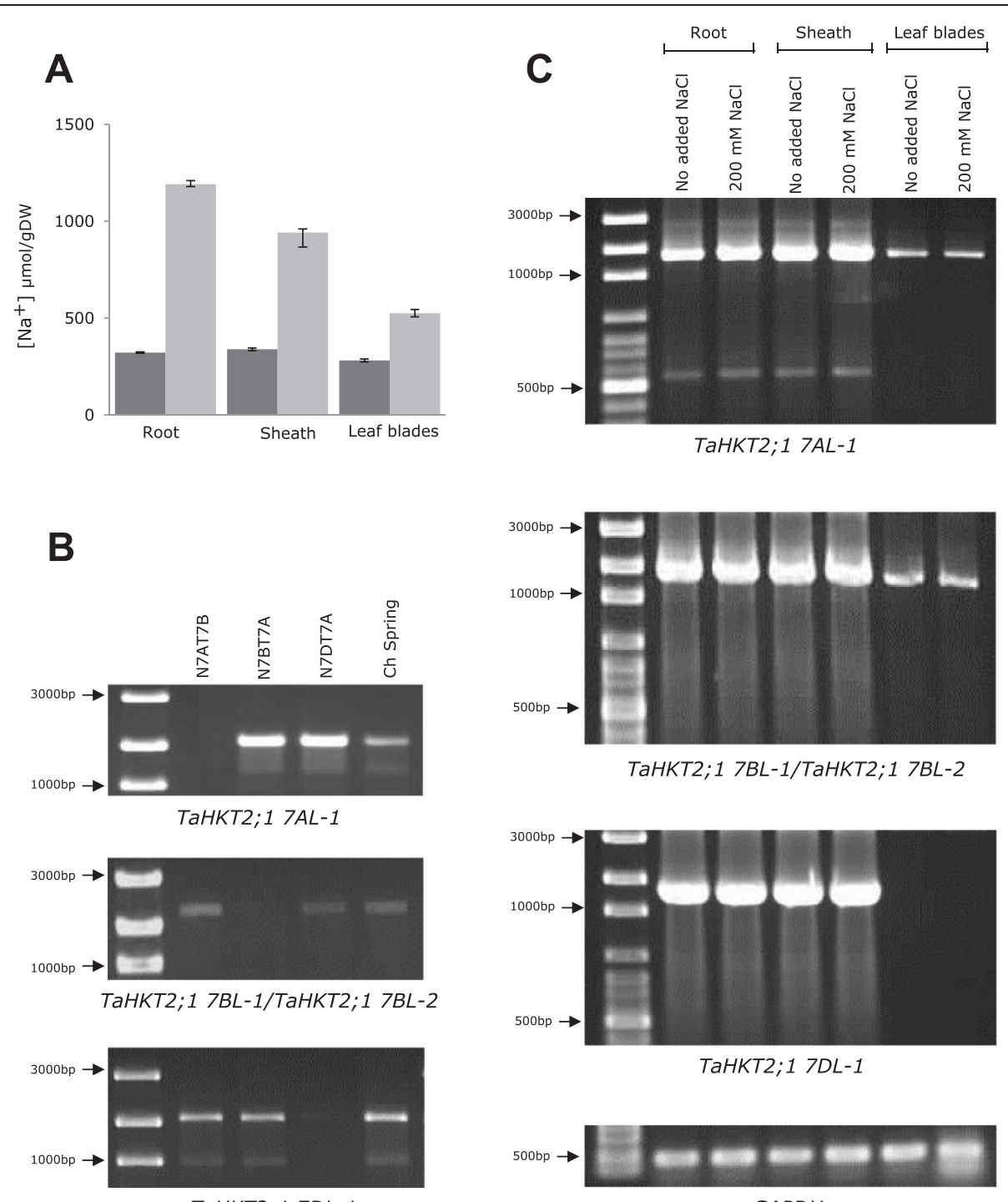

TaHKT2; $17 D L-1$



GAPDH

Figure 4 Transcriptional analysis of TaHKT2;1 gene family in T. aestivum L. cv. Chinese Spring. Tissue samples of each genotype were measured for ion concentration in triplicate and each genotype was replicated four times for each treatment. (A) Tissue $\mathrm{Na}^{+}$concentrations in treatments with no added $\mathrm{NaCl}$ (dark grey) and $200 \mathrm{mM} \mathrm{NaCl}$ (light grey). (B) Nullisomic-tetrasomic analysis of gene specific primers used for transcript analysis. (C) RT-PCR and detection of FL- CDNA in roots, sheaths and leaf blades.

the exon-intron splice junction different to the conserved 5'GT and AG-3' splice junction motifs in all other transcripts.

\section{Tissue ion analyses of wheat aneuploid lines null for TaHKT2; 1 genes}

An investigation of possible phenotypic effects of TaHKT2;1 genes was conducted by evaluating tissue $\mathrm{Na}^{+}$and $\mathrm{K}^{+}$concentrations in wheat aneuploid lines null for each member of the TaHKT2;1 gene family, when exposed to $\mathrm{NaCl}$ and different $\mathrm{K}^{+}$supply in the external solution. The absence of DNA amplicons from aneuploid lines using gene specific PCR primers (Figure 5A) confirmed that TaHKT2;1 $7 A L-1$, and TaHKT2;1 $7 D L-1$ were located in the distal region of 7AL and 7DL respectively, whereas TaHKT2;1 $7 B L-1 /-2$ were located within the proximal region of $7 \mathrm{BL}$ (Figure 5B). Therefore, the aneuploid lines 7AL-1 and Dt7BS were null for the functional genes TaHKT2;1 7AL-1 and TaHKT2;1 7BL-1/-2 respectively, whereas 7DL-2 was null for TaHKT2;1 $7 D L-1$ and suitable for comparing ion concentrations with Chinese Spring under $\mathrm{NaCl}$ and $\mathrm{K}^{+}$ supply.

Analysis of tissue $\mathrm{Na}^{+}$concentration showed no difference between aneuploid lines and Chinese Spring in roots, bulked leaf blades or youngest fully expanded leaf blade regardless of low $(0.2 \mathrm{mM})$ or high $(4 \mathrm{mM}) \mathrm{K}^{+}$status when genotypes were treated with an external solution containing $200 \mathrm{mM} \mathrm{NaCl}$ (Figure 6A). An increase 


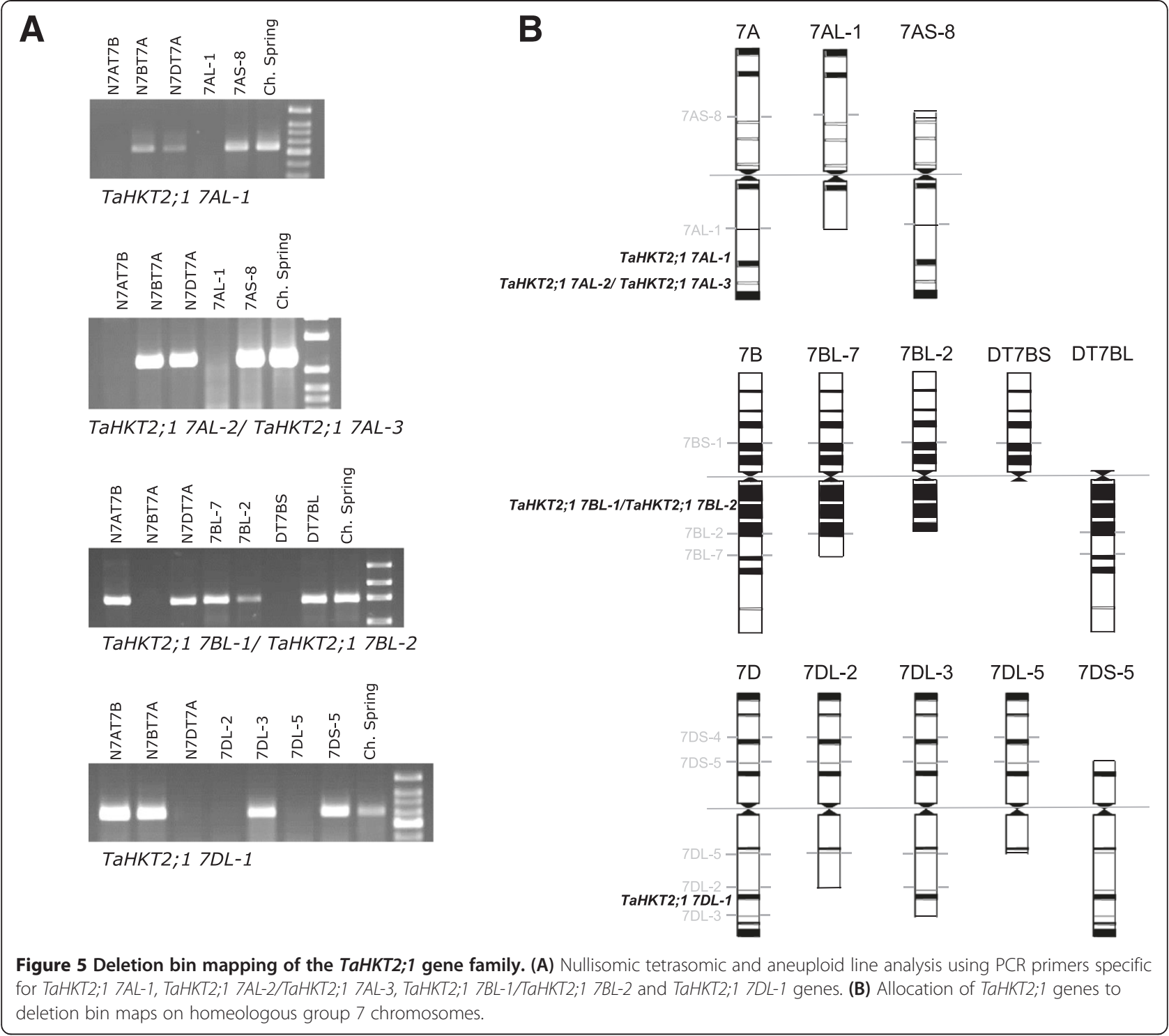

of $24 \%$ in sheath $\mathrm{Na}^{+}$concentration was observed in the aneuploids, 7AL-1 (Figure 6A) compared to Chinese Spring under both low and high $\mathrm{K}^{+}$conditions. Similarly, Dt7BS showed $25 \%$ increase in sheath $\mathrm{Na}^{+}$but only under low $\mathrm{K}^{+}$conditions. Therefore, the chromosomal regions containing TaHKT2;1 7AL-1 and TaHKT2;1 7BL-1/-2 may have a significant effect on $\mathrm{Na}^{+}$concentration in the sheath but not in the roots, bulk leaves nor the youngest fully expanded leaf blade. Interestingly, 7DL-2 null for TaHKT2;1 7DL-1 showed no significant difference between Chinese Spring (Figure 6A) indicating this gene does not have a role in controlling $\mathrm{Na}^{+}$concentration in any tissue or treatment.

The same aneuploid lines when exposed to an external solution containing $200 \mathrm{mM} \mathrm{NaCl}$ and $4 \mathrm{mM} \mathrm{K}^{+}$showed no differences in $\mathrm{K}^{+}$concentration in bulked leaf blades regardless of the genotype or the $\mathrm{Na}^{+}$status (Figure $6 \mathrm{~B}$ ).
However, $\mathrm{K}^{+}$concentration was reduced by $23 \%$ in the roots and $19 \%$ in the youngest fully expanded leaf blade for Dt7BS compared to Chinese Spring, but only under $200 \mathrm{mM} \mathrm{NaCl}$ treatment (Figure 6B). Similarly, sheath $\mathrm{K}^{+}$ was reduced by $12 \%$ in the aneuploid line $7 \mathrm{AL}-1$ in the $200 \mathrm{mM} \mathrm{NaCl}$ treatment (Figure 6B). Therefore, it appears that the chromosomal regions containing TaHKT2;1 7AL1 and TaHKT2;1 7BL-1/-2 influence $\mathrm{K}^{+}$status under high $\mathrm{NaCl}$ conditions in a tissue-specific manner. There was no significant difference in $\mathrm{K}^{+}$between 7DL-2 and Chinese Spring (Figure 6B) indicating that TaHKT2;1 7DL-1 does not have a role in regulating $\mathrm{K}^{+}$status in any tissue and treatments.

\section{Discussion}

This study provides a detailed characterization of the TaHKT2;1 multigene family in bread wheat which 
A
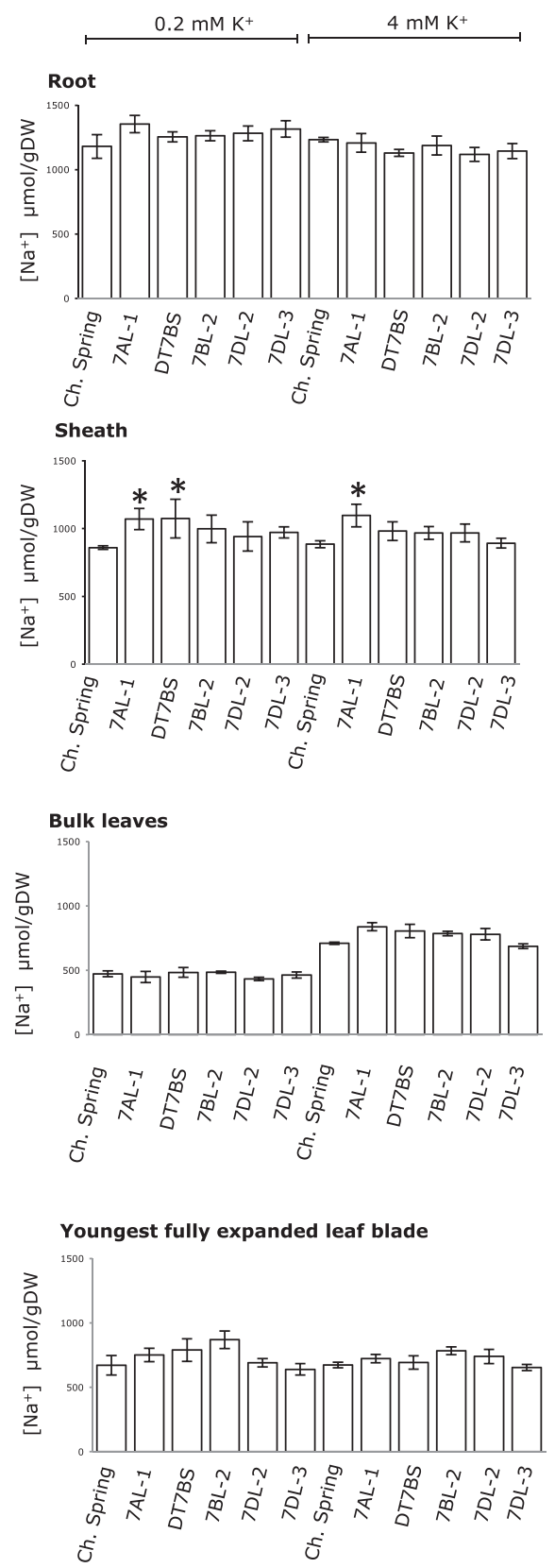

B

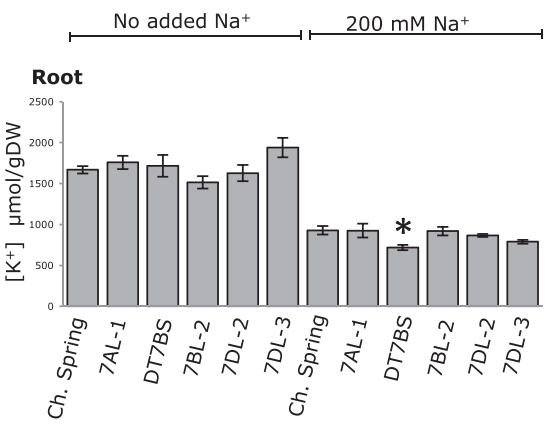

Sheath
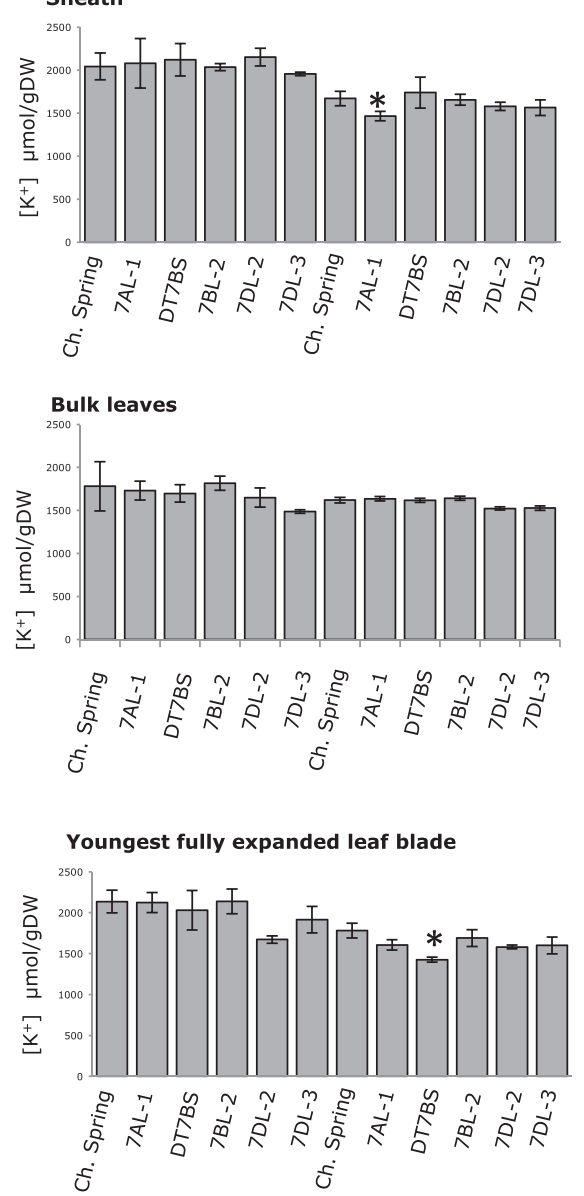

Figure 6 Analysis of ion concentration in tissues from Chinese Spring and wheat aneuploid lines null for each functional TaHKT2;1 genes. Tissue samples of each genotype were measured for ion concentration in triplicate and each genotype was replicated four times for each salt treatment. (A) Mean $\mathrm{Na}^{+}$concentrations ( \pm SE) of various tissues of each genotype subjected to $200 \mathrm{mM} \mathrm{NaCl}$ treatment in the presence of $0.2 \mathrm{mM}$ or $4 \mathrm{mM} \mathrm{K}^{+}$. (B) Mean $\mathrm{K}^{+}$concentrations ( $\pm \mathrm{SE}$ ) of various tissues of each genotype subjected to $4 \mathrm{mM} \mathrm{K}^{+}$treatment in no added $\mathrm{Na}^{+}$in or the presence of $200 \mathrm{mM} \mathrm{NaCl}$. Significant differences in tissue concentrations of $\mathrm{Na}^{+}(p<0.01, \mathrm{CV}=16)$ and $\mathrm{K}^{+}(p<0.05, \mathrm{CV}=11)$ between the aneuploids and Chinese Spring are indicated by an asterisk (*).

included four functional members and two pseudogenes. Despite presence of salt induced stress responsive elements in the promoter region it was found that the functional members of the TaHKT2;1 family were expressed under low and high $\mathrm{NaCl}$ levels in roots and sheaths, but were down regulated in leaf blades. Wheat aneuploid lines were used to provide evidence for a potential role of individual TaHKT2;1 gene family members in $\mathrm{Na}^{+}$and $\mathrm{K}^{+}$homeostasis in seedlings under low and high $\mathrm{NaCl}$ hydroponic conditions.

Although all members of the TaHKT2;1 gene family contained three exons and two introns sharing the same 
gene structure as Group II HKT genes from other monocots [33], DNA sequence differences resulted in a degree of variability at the protein level. Variation amongst the TaHKT2; 1 genes and their encoded proteins could be of functional relevance. TaHKT2; 1 proteins potentially acting as $\mathrm{K}^{+} / \mathrm{Na}^{+}$cotransporters have a conserved Gly-Gly-Gly-Gly signature in the selectivity filter, yet the filter signature alone does not necessarily predict ion selective properties and other domains responsible for ion specificity need to be considered $[34,35]$. In this regard, induced mutations within the cytoplasmic (L149, E180) or P-loop (A240, L247, F463 and E464) domains affected selectivity and the rate of uptake of $\mathrm{K}^{+}$and $\mathrm{Na}^{+}$by the TaHKT2;1 7BL-1/-2 proteins in yeast and/or Xenopus oocytes heterologous systems $[17,19,21,23,36,37]$. Interestingly, the majority of the amino acids that were mutated in previous experiments were conserved between the members of TaHKT2;1 family except for a A240S substitution in TaHKT2;1 7DL-1. In addition to A240S, five amino acid differences were identified within six base pair proximity to the filter glycine residues in the P-loops of TaHKT2;1 $7 A L-1$, TaHKT2;1 7DL-1 compared to TaHKT2;1 7BL$1 /-2$. Therefore, it is reasonable to hypothesize that the amino acid differences between members of the TaHKT2;1 gene family in these regions may affect ion uptake properties (e.g. specificity and rate of ion transport). Since this study cloned FL-cDNAs of each member of the gene family, further investigations can be pursued using heterologous systems to evaluate the functional significance of the protein sequence variability for ion transport in the TaHKT2;1 gene family.

TaHKT2;1 7AL-2 and TaHKT2;1 7AL-3 shared typical characteristics of unprocessed pseudogenes, such as inframe stop codons, location within close proximity to the functional genes on the same chromosome, and the absence of transcription [38]. Pseudogenes have previously been reported in the $H K T$ super-family but their functional relevance is unknown [39]. Pseudogenes are thought to be an integral feature in evolution of polyploidy genomes, representing $12 \%$ of the genes in bread wheat [40] and may be of importance in gene or genome function. Pseudogenes in eukaryotes have been reported to have a regulatory role for genes from which they were derived, have non-coding functions or act as a source of genetic variability and were subjected to natural selection [38]. Conservation across progenitor genomes indicated that the single base deletion in exon 1 that caused a pre-mature stop codon in TaHKT2;1 7AL-2 and TaHKT2;1 7AL-3 was an ancient event created during evolution of the A genome progenitor species prior to, and maintained during, polyploidization of the tetraploid and hexaploid genomes. The $\mathrm{Ka} / \mathrm{Ks}$ between the functional genes was close to the average $\mathrm{Ka} / \mathrm{Ks}$ ratio of 0.2 previously estimated for functional wheat genes [41], providing evidence that the functional members of the TaHKT2;1 gene family was subjected to resilient purifying selection. Although TaHKT2;1 7AL-2 and TaHKT2;1 $7 A L-3$ had characteristics of pseudogenes the $\mathrm{Ka} / \mathrm{Ks}$ value between these genes and TaHKT2;1 7AL-1 was less than the theoretical value of 1.0 for a bona-fide pseudogene [38], indicating a relaxed selective constraint during genome evolution. Furthermore, the fact that these pseudogenes were retained during evolution of the hexaploid wheat genome with gene structure conservation could indicate some functional importance.

Each member of the TaHKT2;1 gene family was variable for presence and frequency of salt induced CREs. Plant response to salinity is mediated by immediate and extensive reprogramming of the spatial and temporal gene transcription, instigated by the interaction of transcription factors with four major groups of CREs including ABA-independent CREs (CBF/DREB; NAC and ZFHD) and ABA-dependent CREs (AREB/ABF; MYC/ MYB) [42,43], all of which were represented in TaHKT2;1 gene family. Interestingly, promoter diversity in AtHKT1;1 genes resulted in variable salt response in natural populations of Arabidopsis [44]. Similarly, variability in CREs contributed to diverse expression patterns of TaHKT1;5 in bread wheat and wild relatives under salt stress [45], supporting the hypothesis that $H K T$ genes are regulated by CREs mediated mechanisms. The presence of these elements with varying copies and combinations predict salt response with variable expression patterns of individual TaHKT2;1 members.

Given the CREs identified in this study, it was expected that each TaHKT2;1 gene would show diverse transcriptional regulation, yet, no obvious transcript differences were detected between low and high $\mathrm{NaCl}$ treated plants. Similar observations were reported [24] where saline treatments imposed with $\mathrm{K}^{+}$deficient conditions did not induce differences in TaHKT2; 1 gene expression in two week old wheat seedlings. However, expression of TaHKT2;1 $7 B L-1 /-2$ was up regulated by imposing $\mathrm{K}^{+}$starved conditions in six day old wheat [46] indicating a rapid response of genes to external $\mathrm{K}^{+}$in younger seedlings. In the present study, there was an obvious down regulation of TaHKT2;1 transcripts in leaf blades regardless of the $\mathrm{NaCl}$ concentration of the external solution, confirming adjustment of gene expression in this tissue. The extent of gene expression was further explored by mining wheat EST databases including NCBI, Transcriptome Shotgun Assembly and the TIGR Plant Transcript Assemblies, identifying a number of ESTs derived from pre-anthesis spikes and kernel tissue with $98-100 \%$ identity to members of the TaHKT2;1 gene family (data not shown). Further studies are needed to understand the expression of TaHKT2;1 gene family 
and how the various members influence ion homeostasis during different stages of plant development, various environmental conditions and variable salt levels.

An interesting feature of TaHKT2;1 gene expression was the level of complexity caused by alternative splicing of a $571 \mathrm{bp}$ transcript unique to TaHKT2;1 7AL-1. Alternative splicing is evident in 25 to $42 \%$ of bread wheat genes whereby some forms are thought to play a role in regulating functional transcript levels [47]. Alternative splicing at non-conventional-splice junctions has been reported in rice OsHKT1;5 resulting in a premature stop codon and non-functional transcripts as a possible means of regulating mRNA degradation [34]. Similarly, alternative splicing event in TaHKT2;1 7AL-1 indicates a rare unstable splice-junction motif that may act as an embedded molecular switch for post-transcriptional regulation and mRNA turn-over processes, which presumably may then influence levels of protein production.

The use of wheat aneuploid lines null for specific members of the TaHKT2;1 family provided a system to analyse phenotypic effects of the genes on tissue ion concentrations. This approach provided evidence that a gene does not have a specific role when there was no significant difference between its corresponding aneuploid line and Chinese Spring (containing the full chromosome complement) whereas differences indicated that the gene would be a candidate controlling tissue $\mathrm{Na}^{+}$ and/or $\mathrm{K}^{+}$status. The results, therefore, corroborate that TaHKT2; 1 genes neither regulate root $\mathrm{Na}^{+}$uptake nor $\mathrm{Na}^{+}$accumulation in bulk leaf blades and youngest fully expanded leaf blade. Nevertheless, presence of transcripts for all TaHKT2;1 gene family members in these tissues under low and high $\mathrm{NaCl}$ conditions indicate alternative roles if they are translated into proteins. The higher sheath $\mathrm{Na}^{+}$concentration in 7AL-1 and Dt7BS is likely from increased $\mathrm{Na}^{+}$concentration in the xylem flow and being preferentially stored in sheaths. Wheat and other grasses do have mechanisms for withdrawal of $\mathrm{Na}^{+}$from xylem in roots and sheath to reduce delivery of $\mathrm{Na}^{+}$into the leaf blade [48]. Therefore, TaHKT2;1 7AL-1 and TaHKT2;1 $7 B L-1 /-2$ genes are candidates regulating $\mathrm{Na}^{+}$accumulation in sheaths, perhaps by modifying $\mathrm{Na}^{+}$in the root xylem that affects the flow of $\mathrm{Na}^{+}$into sheaths. The possibility of other genes in the same chromosomal region contributing to this phenotypic effect cannot be excluded and further studies are needed to confirm the function of TaHKT2; 1 genes on 7AL and 7BL in controlling $\mathrm{Na}^{+}$accumulation in the sheaths.

The TaHKT2;1 7AL-1 gene may also regulate $\mathrm{K}^{+}$accumulation in the sheath but only under high $\mathrm{NaCl}$ conditions, whereas TaHKT2;1 7BL-1/-2 may serve a similar role in roots and the youngest fully expanded leaf blade, evident by the lower $\mathrm{K}^{+}$in these tissues in the Dt7BS line. Since TaHKT2;1 genes are not involved in $\mathrm{K}^{+}$ uptake by roots under saline conditions $[18,49]$, the lower root $\mathrm{K}^{+}$concentration observed for Dt7BS in this study would be due to a greater net $\mathrm{K}^{+}$translocation from roots to shoots. Therefore, it is reasonable to assume that TaHKT2;1 7BL-1/ TaHKT2;1 7BL-2 genes control $\mathrm{K}^{+}$translocation in specific tissues of salt stressed wheat. Extensive functional redundancy of $\mathrm{K}^{+}$transport systems [50] can be a challenge in isolated studies on individual transporter proteins, yet evidence in the present study identified the importance of further investigating TaHKT2;1 7BL-1/TaHKT2;1 7BL-2 and TaHKT2;1 7AL-1 genes in controlling $\mathrm{K}^{+}$homeostasis.

\section{Conclusions}

TaHKT2;1 genes has been of interest because the encoded proteins implement pathways for $\mathrm{Na}^{+}$entry into wheat in saline conditions [24]. However, previous studies do not recognize a role of individual members of the TaHKT2;1 gene family in controlling $\mathrm{Na}^{+}$or indeed, of $\mathrm{K}^{+}$, during plant growth and development. The present study has highlighted diversity amongst the TaHKT2;1 gene family and predicted proteins, as well as promoter variability in salt signalling and presence of TaHKT2;1 transcripts in different tissues, under low and high levels of external $\mathrm{Na}^{+}$ and $\mathrm{K}^{+}$, gaining knowledge that TaHKT2;1 genes could assume multiple roles in bread wheat. The phenotypic effects when individual genes were deleted in bread wheat showed that TaHKT2;1 gene family are not involved in regulating root or leaf blade $\mathrm{Na}^{+}$concentration but TaHKT2;1 7AL-1 and TaHKT2;1 7BL-1/-2 may be candidate genes controlling sheath $\mathrm{Na}^{+}$concentration and $\mathrm{K}^{+}$status in different tissues and experimental conditions. TaHKT2;1 7DL-1 had no apparent role in regulating $\mathrm{Na}^{+}$and $\mathrm{K}^{+}$status in different tissue and treatments in this study. In summary, the present findings from combined molecular and physiological studies provided a broader perspective of the role of the TaHKT2;1 family of genes in bread wheat.

\section{Methods}

\section{Plant material}

Bread wheat variety Triticum aestivum L. cv. Chinese Spring, six nullisomic-tetrasomic lines (N7AT7B, N7AT7D, N7BT7A, N7BT7D, N7DT7A, N7DT7B), eight deletion lines (7AL-1, 7AS-8, 7BL-2, 7BL-7, 7DL-2, 7DL-3, 7DL-5, 7DS-5) and ditelosomic lines (Dt7BL and Dt7BS) were kindly provided by Dr John Raupp, Wheat Genetic and Genomic Resources Centre, Kansas State University, USA. Six hexaploid cultivated bread wheat varieties Calingiri, Ducula, Krichauff, Westonia, SARC-1 and a tetraploid variety (T. turgidum L.) Tamaroi were obtained from the germplasm collection at the Department of Agriculture and Food, Western Australia. DNA samples of the diploid species, $T$. monococcum (accession 4044) was provided by 
Dr Evans Lagudah, CSIRO Plant Industry, Canberra, Australia.

\section{In-silico analysis of TaHKT2; 1 gene family}

The TaHKT2;1 FL-cDNA, U16709, was used as the query sequence in BLASTN to search IWGSS database (www.wheatgenome.org) and retrieve coding and promoter regions of the individual members of TaHKT2;1 gene family. In-silico gene structure predictions for individual members of the TaHKT2;1 family were made using Spidey (http://www.ncbi.nlm.nih.gov/spidey/), GeneSeqer (http://www.plantgdb.org/cgi-bin/GeneSeqer/index.cg) and SIM4 (http://pbil.univ-lyon1.fr/sim4.php) software. Intron-exon structures for each member were confirmed by aligning retrieved genomic sequences with the FLcDNA, U16709. DNA and protein sequence analysis and structure predictions were made using GENEIOUS 6.0.3 [51] and phylogenetic analysis was performed in MEGA $5.05[52]$.

The predicted proteins were analysed for structural and functional elements including hydrophobicity and membrane topology using TMHMM Server 2.0 (http:// www.cbs.dtu.dk/services/TMHMM/) and MPEx 3.2 [53] (http://blanco.biomol.uci.edu/mpex/) software suites. Three dimensional structures of the proteins were predicted by PHYRE 2 (http://www.sbg.bio.ic.ac.uk/phyre2/html/page. cgi?id=index). Protein sequence alignments, hydrophobicity plots and the 3-D structures were used to elucidate structural domains of the putative proteins.

DNA sequence $2000 \mathrm{bp}$ upstream of predicted initiation site were analysed for cis-acting regulatory elements (CREs) associated with salt stress response in PlantCARE [54] and PLACE [55] databases.

\section{DNA extraction and PCR amplification}

Plant genomic DNA was extracted from leaves using a phenol-chloroform-based method as described in [56] and was used as a template for PCR to amplify individual members of the TaHKT2;1 family. Gene specific primer pairs were designed by targeting insertions and/or deletions (INDELs) and single nucleotide polymorphisms (SNPs) based on 3' terminus mismatch described in [57]. NetPrimer (http://www.premierbiosoft.com/ netprimer/netprlaunch/netprlaunch.html) was used to confirm primer compatibility. Primer information is summarized in Table 1. PCR reactions contained $1.5 \mathrm{mM}$ $\mathrm{MgCl}_{2}, 0.2 \mathrm{mM}$ of each deoxyribonucleotides, $10 \mu \mathrm{M}$ of each primer, 1X PCR buffer, $0.1 \mathrm{U}$ taq DNA polymerase (BIOTAQ $^{\mathrm{mm}}$ DNA Polymerase, Bioline, Australia) and $50 \mathrm{ng}$ of template DNA in a $20 \mu \mathrm{l}$ reaction volume. Cycle conditions for standard PCR were 35 cycles of $94^{\circ} \mathrm{C}$ $30 \mathrm{sec}$, primer annealing temperature $30 \mathrm{sec}, 72^{\circ} \mathrm{C} 30 \mathrm{sec}$ and the final extension $7 \mathrm{~min}$ at $72^{\circ} \mathrm{C}$; and for touchdown PCR were five cycles of $94^{\circ} \mathrm{C} 30 \mathrm{sec}, 55-50^{\circ} \mathrm{C} 30 \mathrm{sec}, 72^{\circ} \mathrm{C}$
$30 \mathrm{sec}$; and then 35 cycles of $94^{\circ} \mathrm{C} 30 \mathrm{sec}, 50^{\circ} \mathrm{C} 30 \mathrm{sec}$, $72^{\circ} \mathrm{C} 30 \mathrm{sec}$ and the final extension $7 \mathrm{~min}$ at $72^{\circ} \mathrm{C}$. PCR products were separated on $1.5 \%$ agarose gel in $0.5 \mathrm{X}$ Trisacetate EDTA at constant voltage $(90 \mathrm{~V})$ for $30 \mathrm{~min}$ and visualized under UV light using Gel Doc System (BioRad, Italy) after staining with ethidium bromide.

\section{Hydroponic screening and tissue $\mathrm{Na}^{+}$and $\mathrm{K}^{+}$analysis of wheat aneuploid lines null for TaHKT2;1 genes}

Seeds of six selected wheat deletion and ditelosomic lines were washed in $0.04 \%$ sodium hypochlorite $(42 \mathrm{~g} / \mathrm{L})$ for $30 \mathrm{sec}$, rinsed in deionized water, and placed on a mesh float on aerated 0.1 strength nutrient solution in the dark for three days. Seedlings were then transferred to 0.25 strength nutrient solution for one day. Nutrient composition at full strength was: $(\mathrm{mM}) \mathrm{K}^{+}, 3.95 ; \mathrm{Ca}^{2+}, 4$; $\mathrm{Mg}^{2+}, 0.4 ; \mathrm{NH}_{4}^{+}, 0.625 ; \mathrm{NO}_{3}^{-}, 4.375 ; \mathrm{SO}_{4}^{2-}, 1.9 ; \mathrm{HPO}_{4}^{2-}, 0.2$; Fe-EDTA, 0.05; MES, 1.0; and micronutrients of onequarter-concentration in Hoagland solution $(\mathrm{pH}$ was adjusted to 6.5 using $\mathrm{Ca}(\mathrm{OH})_{2}$ ). Four day old seedlings were then transferred to full strength nutrient solution in aerated, foil-covered, $4.5 \mathrm{~L}$ pots for 12 days. Each pot carried one individual of each of all six genotypes arranged randomly in each pot. There were four replicates of each genotype for each treatment in the experiment and the pots were arranged in a completely randomised design. Seedlings were held upright by a foam holder at the stem base inserted into individual holes in the pot lids. The experiment was carried out in a temperature controlled phytotron $\left(20 \pm 3^{\circ} \mathrm{C} / 15 \pm 2^{\circ} \mathrm{C}\right.$ day/night $)$ and the photosynthetically active radiation (PAR) recorded at midday was at ca. $1,400-1,500 \mu \mathrm{mol} \mathrm{m}{ }^{-2} \mathrm{~s}^{-1}$. Solution levels in pots were maintained by topping up with deionized water.

In order to induce expression and study phenotypic effects of the TaHKT2;1 gene family, the plants were subjected to low $\mathrm{K}^{+}$conditions prior to imposing salt treatments $[24,46]$. As known TaHKT2;1 transporters might be involved with either $\mathrm{Na}^{+}$and/or $\mathrm{K}^{+}$transport $[16,21,22] \mathrm{NaCl}$ treatments were also imposed at the two $\mathrm{K}^{+}$levels: low $(0.2 \mathrm{mM}) \mathrm{K}^{+}$, where high affinity transport systems for $\mathrm{K}^{+}$dominate and high $(4 \mathrm{mM}) \mathrm{K}^{+}$, where $\mathrm{K}^{+}$ uptake kinetics was determined by low affinity systems [58]. 12 day old seedlings were subjected to low $\mathrm{K}^{+}$conditions for four days in a modified nutrient solution without added $\mathrm{K}^{+}$. The media contained $(\mathrm{mM}) \mathrm{Ca}^{2+}, 4$; $\mathrm{Mg}^{2+}, 0.4 ; \mathrm{NH}_{4}^{+}, 0.825 ; \mathrm{NO}_{3}^{-}, 4.375 ; \mathrm{SO}_{4^{-}}^{2}, 0.4 ; \mathrm{HPO}_{4^{-}}^{2}$, 0.2; Fe-EDTA, 0.05; MES, 1.0; and micronutrients at one-quarter-concentrations in Hoagland solution $(\mathrm{pH}=$ 6.5 , adjusted with $\mathrm{Ca}(\mathrm{OH})_{2}$ ) at a background $\mathrm{Na}^{+}$and $\mathrm{K}^{+}$ concentrations of $0.3 \mathrm{mM}$ and $0.1 \mathrm{mM}$, respectively. After 4 days of low $\mathrm{K}^{+}$level pre-treatment, $200 \mathrm{mM} \mathrm{NaCl}$ was applied to designated pots, so as to obtain four different $\mathrm{Na}^{+} / \mathrm{K}^{+}$combinations: no added $\mathrm{Na}^{+} / 0.2 \mathrm{mM} \mathrm{K} \mathrm{K}^{+}$, no added $\mathrm{Na}^{+} / 4 \mathrm{mM} \mathrm{K} \mathrm{K}^{+}, 200 \mathrm{mM} \mathrm{Na} / 0.2 \mathrm{mM} \mathrm{K}{ }^{+}$and 
$200 \mathrm{mM} \mathrm{Na}^{+} / 4 \mathrm{mM} \mathrm{K}^{+}$. The $\mathrm{NaCl}$ treatment was applied in $50 \mathrm{mM}$ increments at 12 hour intervals and plants were maintained at the final $200 \mathrm{mM}$ concentration for a full 3 days. The youngest fully expanded leaf blade, bulk leaf blades (all others), sheaths and roots of each plant were sampled. Prior to excision, roots were washed three times for 10 secs each in a solution containing $4 \mathrm{mM} \mathrm{CaSO}_{4}$ and $368 \mathrm{mM}$ mannitol (200 $\mathrm{mM}$ treated plants) or in $4 \mathrm{mM} \mathrm{CaSO}_{4}$ (plants subjected to no added $\mathrm{NaCl}$ ). Leaves and sheath samples were rinsed in deionized water. All tissue samples for ion analyses were oven-dried at $70^{\circ} \mathrm{C}$, weighed and then ground to a powder. Samples of dried powdered tissue $(100 \mathrm{mg})$ were extracted in $5 \mathrm{ml}$ of $0.5 \mathrm{M}$ $\mathrm{HNO}_{3}$ for 3 days on a mechanical shaker. $\mathrm{Na}^{+}$and $\mathrm{K}^{+}$ were measured in technical triplicate using a flame photometer (Sherwood 410, Cambridge) and mean values represented each treatment replicate tissue sample. The reliability of the methods was confirmed by analyses of a reference tissue (broccoli, ASPAC Plant number 85) taken through the same procedures. Mean values from 4 treatment replicates of each genotype were analysed by ANOVA using SAS 9.4 (SAS Inc., USA) software.

\section{RNA extraction and RT-PCR}

T. aestivum var. Chinese Spring was grown in hydroponics and treated with $\mathrm{NaCl}$ as described above. Leaf blades (including youngest fully expanded leaf blade), sheaths and roots of plants treated with $4 \mathrm{mM} \mathrm{K}^{+}$with no added $\mathrm{Na}^{+}$and $4 \mathrm{mM} \mathrm{K}^{+}$with $200 \mathrm{mM} \mathrm{NaCl}$ were harvested after treating the plants for three days, snap frozen in liquid nitrogen for RNA extraction and RT-PCR. Duplicate tissue samples were harvested for $\mathrm{Na}^{+}$analysis (described above). Total RNA was isolated using RNeasy Plant Mini Kit (Qiagen, Hilden, Germany). First strand cDNA was synthesised using RT Omniscript Kit (Qiagen, Hilden, Germany). Integrity of synthesised cDNA was verified by RT-PCR using primers (forward 5'-CGCC AGGGTTTTC CCAGTCAC GAC -3', reverse 5'-TCAC ACAGGAAAC AGCTATGAC -3') designed for glyceraldehyde-3-phosphate dehydrogenase (GAPDH) gene [59]. FL- cDNA of individual members of the TaHKT2;1 gene family were amplified from cDNA preparations using primer pairs FL:A1 $\mathrm{F}$ and FL:A1 R, FL:A2/3 F and FL:A2/3R, FL:B1/2 F and FL:B1/2 R and FL:D1 F and FL:D1 R (Table 1).

\section{FL-CDNA cloning and sequencing}

RT-PCR amplicons were separated and excised from 1\% agarose gels, purified using Wizard ${ }^{\circ} \mathrm{SV}$ Gel and PCR Clean-Up System (Promega, CA,USA), and cloned into pGEM ${ }^{\circ} \mathrm{T}$ Easy Vector Systems (Promega, CA, USA). Three bacterial colonies containing cloned TaHKT2;1 FL-cDNA were selected and DNA templates were purified using Wizard ${ }^{\circ}$ Plus SV Minipreps (Promega, CA, USA). The cloned fragments were sequenced using BigDye ${ }^{\mathrm{Tm}}$ sequencing chemistry (Applied Biosystems, Perkin Elmer, Weiterstadt, Germany) and analysed using GENEIOUS 6.0.3 [51].

\section{Additional file}

Additional file 1: Figure S1. Hydrophobicity of predicted proteins from the functional members of the TaHKT2;1 gene family.

\section{Competing interests}

The authors declare they have no competing interests.

\section{Authors' contributions}

HACKA conducted the bioinformatic work, designed the experiments, generated and analysed data, interpreted results and wrote the manuscript. TUH contributed to designing and conducting experiments for transcript analysis. TDC contributed to designing phenotyping experiments, data interpretation and edited the manuscript. MGF contributed to design of all experiments, data interpretation and edited the manuscript. All authors read, revised and approved the final manuscript.

\section{Acknowledgments}

This work was partly funded by a Scholarship for International Research Fees (SIRF) and a University International Stipend (UIS) awarded to HACKA and a postdoctoral fellowship from the Higher Education Commission (HEC) of Pakistan awarded to TUH. The authors are grateful to Dr Klaus Oldach for critically reviewing the manuscript.

\section{Author details}

${ }^{1}$ School of Plant Biology and Institute of Agriculture, The University of Western Australia, Crawley 6009, Western Australia. ${ }^{2}$ State Agricultural Biotechnology Centre, Murdoch University, Murdoch 6150, Western Australia. ${ }^{3}$ College of Agriculture, D. G. Khan, University of Agriculture Faisalabad, Faisalabad 38040, Pakistan. ${ }^{4}$ Department of Agriculture and Food Western Australia, South Perth 6151, Western Australia.

Received: 2 April 2014 Accepted: 4 June 2014 Published: 11 June 2014

\section{References}

1. Maathuis $\mathrm{F}$, Amtmann $\mathrm{A}: \mathrm{K}^{+}$nutrition and $\mathrm{Na}^{+}$toxicity: the basis of cellular $\mathrm{K}^{+} / \mathrm{Na}^{+}$ratios. Ann Bot 1999, 84:123-133.

2. Tester $\mathrm{M}$, Davenport $\mathrm{R}: \mathrm{Na}^{+}$tolerance and $\mathrm{Na}^{+}$transport in higher plants. Ann Bot 2003, 91:503-527.

3. Munns R: Comparative physiology of salt and water stress. Plant Cell Environ 2002, 25:239-250.

4. Munns R, Tester M: Mechanisms of salinity tolerance. Annu Rev Plant Biol 2008, 59:651-681.

5. Plett C, Moller D, Skrumsager I: $\mathrm{Na}^{+}$transport in glycophytic plants: what we know and would like to know. Plant Cell Environ 2010, 33:612-626.

6. Kronzucker HJ, Britto DT: Sodium transport in plants: a critical review. New Phytol 2011, 189:54-81.

7. Zhang J-L, Flowers TJ, Wang S-M: Mechanisms of sodium uptake by roots of higher plants. Plant Soil 2010, 326:45-60.

8. Amtmann A, Sanders D: Mechanisms of $\mathrm{Na}^{+}$uptake by plant cells. Adv Bot Res 1998, 29:75-112.

9. Tyerman SD, Skerrett M, Garrill A, Findlay GP, Leigh RA: Pathways for the permeation of $\mathrm{Na}^{+}$and $\mathrm{Cl}^{-}$into protoplasts derived from the cortex of wheat roots. J Exp Bot 1997, 48:459-480.

10. Tyerman S, Skerrett I: Root ion channels and salinity. Sci Hortic 1998, 78:175-235.

11. Buschmann PH, Vaidyanathan R, Gassmann W, Schroeder Jl: Enhancement of $\mathrm{Na}^{+}$uptake currents, time-dependent inward-rectifying $\mathrm{K}^{+}$channel currents, and $\mathrm{K}^{+}$channel transcripts by $\mathrm{K}^{+}$starvation in wheat root cells. Plant Physiol 2000, 122:1387-1398.

12. Schachtman DP, Kumar R, Schroeder Jl, Marsh EL: Molecular and functional characterization of a novel low-affinity cation transporter (LCT1) in higher plants. Proc Natl Acad Sci 1997, 94:11079-11084. 
13. Amtmann A, Fischer M, Marsh EL, Stefanovic A, Sanders D, Schachtman DP The wheat CDNA LCT1 generates hypersensitivity to sodium in a saltsensitive yeast strain. Plant Physiol 2001, 126:1061-1071.

14. Schachtman DP, Schroeder J: Structure and transport mechanism of a high-affinity potassium uptake transporter from higher plants. Nature 1994, 370:655-658

15. Demidchik V, Maathuis FJ: Physiological roles of nonselective cation channels in plants: from salt stress to signalling and development. New Phytol 2007, 175:387-404

16. Almeida $\mathrm{P}$, Katschnig $\mathrm{D}$, de Boer AH: HKT transporters- state of the art. Int J Mol Sci 2013, 14:20359-20385.

17. Gassmann W, Rubio F, Schroeder Jl: Alkali cation selectivity of the wheat root high-affinity potassium transporter HKT1. Plant J 1996, 10:869-882.

18. Maathuis FJ, Verlin D, Smith FA, Sanders D, Fernandez JA, Walker NA: The physiological relevance of $\mathrm{Na}^{+}$coupled $\mathrm{K}^{+}$transport. Plant Physiol 1996, 112:1609-1616.

19. Kato $Y$, Sakaguchi M, Mori $Y$, Saito $K$, Nakamura T, Bakker EP, Sato $Y$, Goshima S, Uozumi N: Evidence in support of a four transmembranepore-transmembrane topology model for the Arabidopsis thaliana $\mathrm{Na}^{+} / \mathrm{K}^{+}$ translocating AtHKT1 protein, a member of the superfamily of $\mathrm{K}^{+}$ transporters. Proc Natl Acad Sci 2001, 98:6488-6493.

20. Mäser P, Hosoo Y, Goshima S, Horie T, Eckelman B, Yamada K, Yoshida K, Bakker EP, Shinmyo A, Oiki S: Glycine residues in potassium channel-like selectivity filters determine potassium selectivity in four-loop-per-subunit HKT transporters from plants. Proc Natl Acad Sci 2002, 99:6428-6433.

21. Rubio F, Gassmann W, Schroeder Jl: Sodium-driven potassium uptake by the plant potassium transporter HKT1 and mutations conferring salt tolerance. Science 1995, 270:1660-1663.

22. Sassi A, Mieulet D, Khan I, Moreau B, Gaillard I, Sentenac H, Véry A-A: The rice monovalent cation transporter OsHKT2; 4: revisited ionic selectivity. Plant Physiol 2012, 160:498-510

23. Liu W, Schachtman DP, Zhang W: Partial deletion of a loop region in the high affinity $\mathrm{K}^{+}$transporter HKT1 changes ionic permeability leading to increased salt tolerance. J Biol Chem 2000, 275:27924-27932.

24. Laurie S, Feeney KA, Maathuis FJ, Heard PJ, Brown SJ, Leigh RA: A role for HKT1 in sodium uptake by wheat roots. Plant J 2002, 32:139-149.

25. Huang S, Spielmeyer W, Lagudah ES, Munns R: Comparative mapping of HKT genes in wheat, barley, and rice, key determinants of $\mathrm{Na}^{+}$transport, and salt tolerance. J Exp Bot 2008, 59:927-937.

26. Xiong $L$, Ishitani $M$, Zhu J-K: Interaction of osmotic stress, temperature, and abscisic acid in the regulation of gene expression in Arabidopsis. Plant Physiol 1999, 119:205-212

27. Abe H, Urao T, Ito T, Seki M, Shinozaki K, Yamaguchi-Shinozaki K: Arabidopsis AtMYC2 (bHLH) and AtMYB2 (MYB) function as transcriptional activators in abscisic acid signaling. Plant Cell Online 2003, 15:63-78.

28. Dubouzet JG, Sakuma Y, Ito Y, Kasuga M, Dubouzet EG, Miura S, Seki M, Shinozaki K, Yamaguchi-Shinozaki K: OsDREB genes in rice, Oryza sativa L., encode transcription activators that function in drought-, high-salt-and cold-responsive gene expression. Plant J 2003, 33:751-763.

29. Nakashima K, Takasaki H, Mizoi J, Shinozaki K, Yamaguchi-Shinozaki K: NAC transcription factors in plant abiotic stress responses. Biochimica et Biophysica Acta (BBA)-Gene Regulatory Mechanisms 2012, 1819:97-103.

30. Park HC, Kim ML, Kang YH, Jeon JM, Yoo JH, Kim MC, Park CY, Jeong JC, Moon $\mathrm{BC}$, Lee JH: Pathogen-and $\mathrm{NaCl}$-induced expression of the SCaM-4 promoter is mediated in part by a GT-1 box that interacts with a GT-1-like transcription factor. Plant Physiol 2004, 135:2150-2161.

31. Eulgem T, Rushton PJ, Robatzek S, Somssich IE: The WRKY superfamily of plant transcription factors. Trends Plant Sci 2000, 5:199-206.

32. Li W-H: Unbiased estimation of the rates of synonymous and nonsynonymous substitution. J Mol Evol 1993, 36:96-99.

33. Platten JD, Cotsaftis O, Berthomieu P, Bohnert H, Davenport RJ, Fairbairn DJ, Horie T, Leigh RA, Lin H-X, Luan S: Nomenclature for HKT transporters, key determinants of plant salinity tolerance. Trends Plant Sci 2006, 11:372-374.

34. Cotsaftis O, Plett D, Shirley N, Tester M, Hrmova M: A two-staged model of $\mathrm{Na}^{+}$exclusion in rice explained by 3D modeling of HKT transporters and alternative splicing. PLoS One 2012, 7:e39865.

35. Waters S, Gilliham M, Hrmova M: Plant high-affinity potassium (HKT) transporters involved in salinity tolerance: structural insights to probe differences in ion selectivity. Int J Mol Sci 2013, 14:7660-7680.
36. Diatloff $E$, Kumar R, Schachtman DP: Site directed mutagenesis reduces the $\mathrm{Na}^{+}$affinity of $\mathrm{HKT1}$, an $\mathrm{Na}^{+}$energized high affinity $\mathrm{K}^{+}$transporter. FEBS Lett 1998, 432:31-36.

37. Rubio F, Schwarz M, Gassmann W, Schroeder Jl: Genetic selection of mutations in the high affinity $\mathrm{K}^{+}$transporter HKT1 that define functions of a loop site for reduced $\mathrm{Na}^{+}$permeability and increased $\mathrm{Na}^{+}$ tolerance. J Biol Chem 1999, 274:6839-6847.

38. Balakirev ES, Ayala FJ: Pseudogenes: are they "junk" or functional DNA? Annu Rev Genet 2003, 37:123-151.

39. Garciadeblas B, Senn ME, Banuelos MA, Rodríguez-Navarro A: Sodium transport and HKT transporters: the rice model. Plant J 2003, 34:788-801

40. Wicker T, Mayer KF, Gundlach H, Martis M, Steuernagel B, Scholz U, Šimková H, Kubaláková M, Choulet F, Taudien S: Frequent gene movement and pseudogene evolution is common to the large and complex genomes of wheat, barley, and their relatives. Plant Cell Online 2011, 23:1706-1718.

41. Kawaura K, Mochida K, Enju A, Totoki Y, Toyoda A, Sakaki Y, Kai C, Kawai J, Hayashizaki $Y$, Seki M: Assessment of adaptive evolution between wheat and rice as deduced from full-length common wheat cDNA sequence data and expression patterns. BMC Genomics 2009, 10:271.

42. Zou C, Sun K, Mackaluso JD, Seddon AE, Jin R, Thomashow MF, Shiu S-H: Cis-regulatory code of stress-responsive transcription in Arabidopsis thaliana. Proc Natl Acad Sci 2011, 108:14992-14997.

43. Tuteja N: Mechanisms of high salinity tolerance in plants. Methods Enzymol 2007, 428:419-438.

44. Rus A, Baxter I, Muthukumar B, Gustin J, Lahner B, Yakubova E, Salt DE: Natural variants of AtHKT1 enhance $\mathrm{Na}^{+}$accumulation in two wild populations of Arabidopsis. PLoS Genet 2006, 2:e210.

45. Babgohari MZ, Niazi A, Moghadam AA, Deihimi T, Ebrahimie E: Genomewide analysis of key salinity-tolerance transporter (HKT1; 5$)$ in wheat and wild wheat relatives (A and D genomes). In Vitro Cell Dev Biol Plant 2013, 49:97-106.

46. Wang T-B, Gassmann W, Rubio F, Schroeder J, Glass AD: Rapid upregulation of $H K T 1$, a high-affinity potassium transporter gene, in roots of barley and wheat following withdrawal of potassium. Plant Physiol 1998, 118:651-659.

47. Akhunov ED, Sehgal S, Liang H, Wang S, Akhunova AR, Kaur G, Li W, Forrest $\mathrm{KL}$, See D, Šimková H: Comparative analysis of syntenic genes in grass genomes reveals accelerated rates of gene structure and coding sequence evolution in polyploid wheat. Plant Physiol 2013, 161:252-265.

48. James RA, Davenport RJ, Munns R: Physiological characterization of two genes for $\mathrm{Na}^{+}$exclusion in durum wheat, Nax1 and Nax2. Plant Physiol 2006, 142:1537-1547.

49. Haro R, Bañuelos MA, Senn ME, Barrero-Gil J, Rodríguez-Navarro A: HKT1 mediates sodium uniport in roots. Pitfalls in the expression of HKT1 in yeast. Plant Physiol 2005, 139:1495-1506.

50. Gierth $M$, Mäser P: Potassium transporters in plants-Involvement in $\mathrm{K}^{+}$ acquisition, redistribution and homeostasis. FEBS Lett 2007, 581:2348-2356.

51. Kearse M, Moir R, Wilson A, Stones-Havas S, Cheung M, Sturrock S, Buxton S, Cooper A, Markowitz S, Duran C: Geneious Basic: an integrated and extendable desktop software platform for the organization and analysis of sequence data. Bioinformatics 2012, 28:1647-1649.

52. Tamura K, Dudley J, Nei M, Kumar S: MEGA4: molecular evolutionary genetics analysis (MEGA) software version 4.0. Mol Biol Evol 2007, 24:1596-1599.

53. Snider C, Jayasinghe S, Hristova K, White SH: MPEx: a tool for exploring membrane proteins. Protein Sci 2009, 18:2624-2628.

54. Lescot M, Déhais $P$, Thijs $G$, Marchal $K$, Moreau $Y$, van de Peer $Y$, Rouzé $P$, Rombauts S: PlantCARE, a database of plant cis-acting regulatory elements and a portal to tools for in silico analysis of promoter sequences. Nucleic Acids Res 2002, 30:325-327.

55. Higo K, Ugawa Y, Iwamoto M, Korenaga T: Plant cis-acting regulatory DNA elements (PLACE) database: 1999. Nucleic Acids Res 1999, 27:297-300.

56. Francki M, Crasta O, Sharma H, Ohm H, Anderson J: Structural organization of an alien Thinopyrum intermedium group 7 chromosome in US soft red winter wheat (Triticum aestivum L.). Genome 1997, 40:716-722.

57. Huang X-Q, Brûlé-Babel A: Development of genome-specific primers for homoeologous genes in allopolyploid species: the waxy and starch 
synthase II genes in allohexaploid wheat (Triticum aestivum L.) as examples. BMC Res Notes 2010, 3:140.

58. Rains D, Epstein E: Sodium absorption by barley roots: role of the dual mechanisms of alkali cation transport. Plant Physiol 1967, 42:314-318.

59. Nemoto Y, Sasakuma T: Specific expression of glucose-6-phosphate dehydrogenase (G6PDH) gene by salt stress in wheat (Triticum aestivum L.). Plant Sci 2000, 158:53-60.

doi:10.1186/1471-2229-14-159

Cite this article as: Ariyarathna et al:: Characterization of the multigene family TaHKT 2;1 in bread wheat and the role of gene members in plant $\mathrm{Na}^{+}$and $\mathrm{K}^{+}$status. BMC Plant Biology 2014 14:159.

\section{Submit your next manuscript to BioMed Central and take full advantage of:}

- Convenient online submission

- Thorough peer review

- No space constraints or color figure charges

- Immediate publication on acceptance

- Inclusion in PubMed, CAS, Scopus and Google Scholar

- Research which is freely available for redistribution 